\title{
International committee echoes gloomy forecasts
}

Washington

THE study of the environmental consequences of nuclear war made public last week by the Scientific Committee on Problems of the Environment (SCOPE) is the most ambitious attempt yet to arrive at a comprehensive view of the problem. The report will be published in two volumes, and runs to 800 pages (see also p.192). The immediate effects of nuclear explosions and of radioactive fallout are considered, but it is inevitable that most attention will be given to what the study says about nuclear winter and the probable biological consequences for both natural and agricultural ecosystems that would follow. The modelling in the study "extends very greatly" previous work, according to the chairman of the study's steering committee, Sir Frederick Warner of the University of Essex in England.

The principal authors of the report acknowledge the many uncertainties surrounding estimates of the amount of smoke likely to be released from mass fires and its residence time in the atmosphere, two key factors for the nuclear winter principle. But the study found that all model simulations considered suggested "a strong potential for large-scale weather disruptions as a result of smoke injected by post-nuclear fires".

Although simplifications of the models and uncertainties about some physical processes may affect the details of predictions, they "probably do not affect the general character of the calculated atmospheric response". Tentative estimates indicate that for a nuclear exchange in summer months in the Northern Hemisphere with 6,500 megatonne (MT) equivalent of weapons exploded, a temperature drop of between 15 and $35^{\circ} \mathrm{C}$ in the few weeks after an attack is plausible for continental interiors in the northern midlatitudes, with the day-to-day values depending on the presence or otherwise of patchy dense smoke. (But SCOPE does not believe that thresholds in the relation between depth of smoke and the amount of radiation reaching the ground imply that there is an "acceptable" amount of smoke below which cooling effects do not occur.)

Other places in the Northern Hemisphere, especially coastal areas and islands, might experience much smaller temperature drops of between 0 and $5^{\circ} \mathrm{C}$, because of the effects of convection near the ocean/land boundary. But long-term effects might last for years and would slowly spill over into the Southern Hemisphere, even if the attack were limited to the Northern Hemisphere. Effects of a nuclear attack during winter months would typically be half as great as those in summer.

The estimates of temperature effects are based on sophisticated new modelling techniques that include the interaction between absorption of radiation and movement of the atmosphere, smoke represented as originating from regional sources and the use of scavenging rates determined by precipitation predicted by the model.

The new models can also lead to a lofting of the smoke due to warming that leads to a changed atmospheric temperature profile; the tropopause in the Northern Hemisphere can be lowered to $5 \mathrm{~km}$, and the smoke above the new tropopause would not be efficiently scavenged, again leading to longer residence times (and decreased precipitation). The effect is more pronounced in summer because there is more solar energy to loft the smoke.

SCOPE has made new estimates of the quantity of smoke that would probably be produced in mass fires resulting from a $6,000 \mathrm{MT}$ exchange. It arrives at an estimate of from 30 to 150 million tonnes once early scavenging has removed between 30 and 50 per cent of gross input; about 30 million tonnes of the remaining total would be strongly light-absorbent amorphous elemental carbon which, if spread over the Northern Hemisphere, could reduce insolation at the ground by 90 per cent. But the SCOPE authors admit that the effects of early scavenging represent one of the greatest sources of uncertainty, and the parameters are acknowledged as simplistic. Because of the strong concentration of fossil fuels and related products around cities and towns, the near-total burnout of less than one hundred of the

world's largest industrialized areas would cause the burning of 25-30 per cent of the combustible materials of the developed world.

The SCOPE study explicitly disavows the term "nuclear winter", which it says is too restricting for the multitude of possible effects of a nuclear war. The study makes some assessment of the effect of toxic substances other than smoke likely to be produced in a nuclear exchange. Nitrogen oxides, which may destroy atmospheric ozone, are seen as significant. And there are new gamma-ray dose estimates that suggest that under the same 6,000 MT exchange (about half the world's nuclear arsenal), lethal external gamma-ray doses (assuming no protective action) would cover 7 per cent of the land area of the United States, Europe and the Soviet Union. If spent nuclear fuel rods were distributed in the environment, the dose could be trebled. SCOPE also considers the effects of electromagnetic pulses (EMPs) caused by nuclear explosions.

SCOPE breaks new ground in its assessment of the biological consequences of cooling effects. The report considered the effects for a range of possible attack scenarios. Stress due to lowered temperatures, lowered light intensities and increased levels of ultraviolet light is found to have very serious consequences for agricultural systems in particular and, when taken in conjunction with levels of food in store in different countries, threatens starvation on a large scale. Even rather modest decreases in average temperatures - say $5^{\circ} \mathrm{C}$ for a growing season - would, for example, make the cultivation of wheat in Canada impossible. Many staple food crops, especially rice, are extremely vulnerable to temperature shifts, particularly during the growing season.'The report recommends urgent research to clarify the effects of stress on crops as well as a comprehensive programme on the physics of smoke plumes and scavenging.

Tim Beardsley

\section{Soviet missing person}

\section{Washington}

THE SCOPE report on the environmental consequences of nuclear war pays special tribute to the contribution of Vladimir Aleksandrov, the Soviet nuclear winter researcher who mysteriously disappeared in Madrid earlier this year. Asked about Aleksandrov at the press conference announcing the SCOPE report, Sir Frederick Warner of the University of Essex, chairman of the project steering committee, said that Aleksandrov's whereabouts remained a mystery and a source of concern. He immediately offered the question to N. Lukyanov, who (like Aleksandrov before his disappearance) works at the Computer Centre of the Academy of Sciences of the USSR in Moscow. Lukanov said he was an old friend of Alksandrov's but could add nothing to Sir Frederick's statement other than "we miss him".

The absence of information about Aleksandrov did not of course prevent speculation in the corridors of the US National Academy of Sciences, which was host to the 1985 SCOPE general assembly. One theory was that Aleksandrov, who by one account had unexplained conversations with Swedish scientists immediately before his disappearance, had planned to defect to the West. According to this theory, his disappearance was a pre-emptive move by Soviet intelligence services; Aleksandrov's whereabouts are believed to be unknown to the intelligence services of any Western country.
Tim Beardsley 